\title{
Reforming Watershed Restoration: Science in Need of Application and Applications in Need of Science
}

\author{
Margaret A. Palmer
}

Received: 9 November 2008 /Revised: 5 December 2008 /Accepted: 5 December 2008 /Published online: 23 December 2008

(C) Coastal and Estuarine Research Federation 2008

\begin{abstract}
Coastal and inland waters are continuing to decline in many parts of the world despite major efforts made to restore them. This is due in part to the inadequate role that ecological science has played in shaping restoration efforts. A significant amount of fundamental ecological knowledge dealing with issues such as system dynamics, state changes, context-dependency of ecological response, and diversity is both under-used by managers and practitioners and under-developed by ecologists for use in realworld applications. Some of the science that is being 'used' has not been adequately tested. Thus, restoration ecology as a science and ecological restoration as a practice are in need of reform. I identify five ways in which our ecological knowledge should be influencing restoration to a far greater extent than at present including a need to: shift the focus to restoration of process and identification of the limiting factors instead of structures and single species, add ecological insurance to all projects, identify a probabilistic range of possible outcomes instead of a reference condition, expand the spatial scale of efforts, and apply hierarchical approaches to prioritization. Prominent examples of restoration methods or approaches that are commonly used despite little evidence to support their efficacy are highlighted such as the use of only structural enhancements to restore biodiversity. There are also major gaps in scientific knowledge that are of immediate need to policy makers, managers, and restoration practitioners including: predictive frameworks to guide the restoration of ecological processes, identification of social-ecological feedbacks that constrain
\end{abstract}

\section{A. Palmer $(\square)$}

Chesapeake Biological Laboratory,

University of Maryland Center for Environmental Science,

Solomons, MD 20688, USA

e-mail: mpalmer@umd.edu ecosystem recovery and data to support decisions of where and how to implement restoration projects to achieve the largest gains. I encourage ecologists to respond to the demand for their scientific input so that restoration can shift from an engineering-driven process to a more sustainable enterprise that fully integrates ecological processes and social science methods.

Keywords Watershed Restoration - Ecosystem .

Ecological theory $\cdot$ Species diversity $\cdot$ Heterogeneity $\cdot$ Scale

\section{Introduction}

Throughout much of the world, people have relied on the network of freshwater tributaries and tidal waters for recreation, clean drinking water, agricultural production, hydropower, and fisheries. Unfortunately, human activities have impacted watersheds worldwide such that countless rivers are polluted and many coastal oceans have degraded habitat or reduced fisheries. This is despite the tremendous efforts that have been devoted to managing and restoring watersheds and estuaries. Significant investments have been made in improving environmental conditions in waterways as diverse as those in the California Delta region of the United States, the Baltic region in Europe, the subcatchments of Moreton Bay in Australia, and the Mekong River Basin in Asia (Dudgeon 2005; Lotze et al. 2006; Bunn et al. 2007; CalFed 2008).

Why have rivers and coastal waters such as these continued to degrade despite large investments? A variety of responses to that question are commonly heard. Continued development and land use change are certainly contributing factors. Population growth and the movements of people typically lead to elevated pollutant loads and an 
increase in water extractions or diversions (Postel and Richter 2003; Walsh et al. 2005). Over-harvesting of living resources, particularly of keystone species such as bivalves, has also been blamed for the decline of a number of coastal watersheds (Grabowski and Peterson 2007). More recently, this decline has been attributed to narrow management approaches that do not rely on learning and adapting policies in an iterative fashion or that do not apply the precautionary principle (Boesch 2006). As Duarte and Conley (2008) point out, some of the blame should be placed on the scientific community, who in their desire to present a clear enough message to prompt management actions have probably over-simplified ecosystem dynamics. In addition to these explanations, I assert that current approaches to restoration are simply not sufficient and the need for input from scientists has never been greater.

I argue for a major reform in watershed restoration because much of the ecological science that has been produced is not being applied to restore aquatic ecosystems, some of the science that is being 'used' has not been adequately tested and scientists have been slow to produce use-inspired knowledge. By the latter, I mean ecological knowledge generated in response to the immediate needs of restoration practitionersi.e. what Sarewitz and Pielke (2007) would call demanddriven science.

Given that restoration is a relatively young practice, it is not surprising that the demands for science are high or that restoration activities often precede field verification of methods. However, it is surprising that the practice of restoration is largely disconnected from many fundamental ecological concepts because so much ecological theory is directly relevant (Fig. 1). The reasons for the disconnect are complex and may include insufficient communication of scientific findings, a public and management community often unwilling to act on science-based findings, and scientists not producing knowledge that can be readily translated to real-world solutions. While science is not the sole solution to our environmental problems, ecological restoration must be grounded in science. Use of state-ofthe-art knowledge, methods for dealing with uncertainty, predictive frameworks, and quantitative tests of alternatives are core scientific tools essential to repairing damaged ecosystems. Society cannot afford an ad hoc approach to environmental management - the costs to the economy and ultimately to human health will simply be too high.

I outline elements of a more rigorous approach to restoration that requires scientists to identify when and how fundamental ecological knowledge is under-utilized, to scope out and test common restoration practices that have been inadequately evaluated or are based on faulty scientific logic, and to recognize the needs of practitioners then allow those needs to stimulate new science. I begin by focusing on three broad areas that encompass bodies of ecological knowledge pivotal to successful restoration: system dynamics, scale and context-dependency, and diversity. For each, I provide a brief overview of the relevant ecological theory, concepts, and results from research then describe the relevance to restoration in practice including the extent to which theories are being applied, ignored, or misused. My examples are admittedly biased toward my expertise, namely running waters that make up the many tributaries feeding coastal zones. Treatment of fisheries "restoration" is better left to those more knowledgeable who can meld principles of harvest management and stock assessment with ecosystem restoration.

\section{Ecological Theory as a Foundation for Restoration Science}

Strictly speaking, ecological restoration is an attempt to return a system to some historical state, although it is
Fig. 1 The science of restoration ecology draws from bodies of theory in diverse disciplines including ecology, hydrology, geomorphology, and, more recently, social science. The goal is to develop and test theories that will contribute to the ecological restoration of habitats, species, and entire ecosystems. Specific examples of ecological theory and their application to various steps in a restoration project are shown

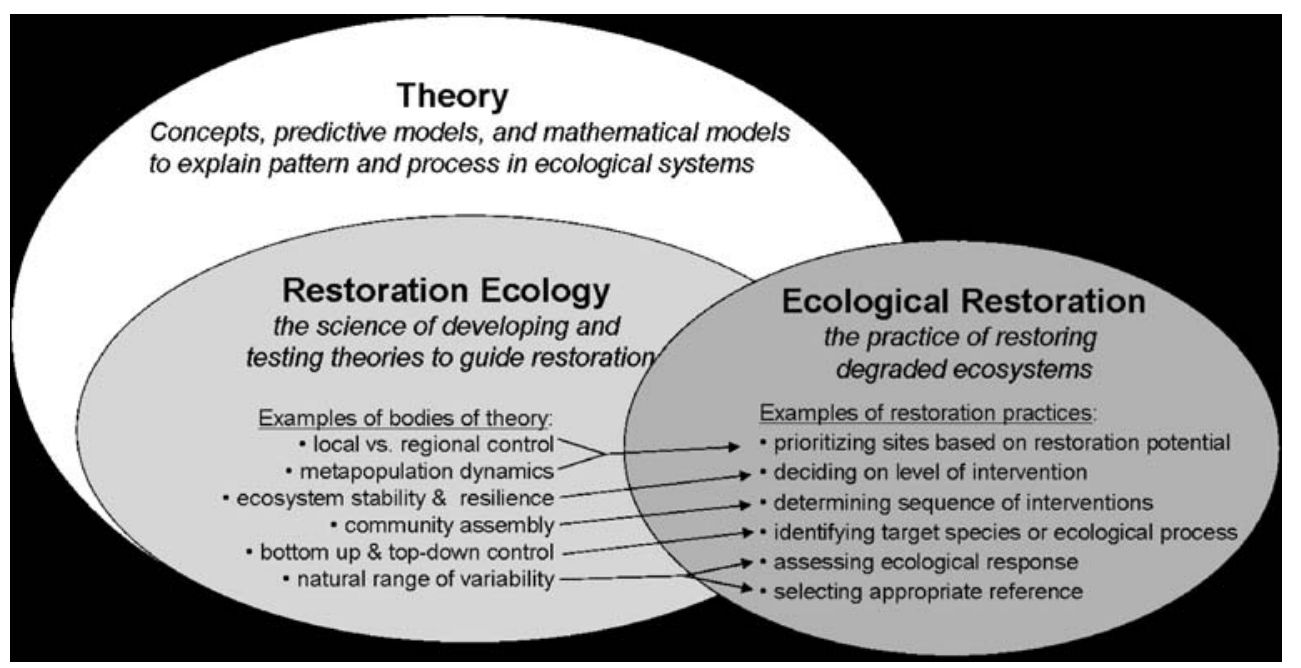


widely recognized that this is often difficult or even impossible to achieve. A more realistic goal may be to move a damaged system to an ecological state that is within acceptable limits relative to a less-disturbed system. In this sense, ecological restoration can be viewed as an attempt to shift ecosystem composition, structure, and function to within a range that is more desirable than current conditions.

The scientific underpinnings of ecological restoration can be found in ecological theory writ large. By the latter, I mean to include the interactions of physical processes (hydrological and geomorphic) with ecological processes and players. Ecological science has a long history of using theory to guide and advance knowledge and so today there is a strong and diverse body of theory addressing many aspects of ecological interactions (Weiner 1995; McGlade 1999; May and McLean 2007). These theories typically fall into two groups: mathematical descriptions of phenomena or conceptual descriptions of nature. Both are used to build and test predictions. I will focus on the broader category of ecological concepts and the extent to which they inform restoration in practice, but I acknowledge that many restoration efforts focused on single species have been informed by population dynamics modeling that was a direct outgrowth of ecological theory (Falk et al. 2006). For example, population viability analysis can be used to evaluate different restoration strategies (Maschinski and Wright 2006).

Ecological theory as it applies to restoration includes principles of population, community, and ecosystems ecology with the former two contributing insights mainly on the roles of recruitment, dispersal, and species interactions (Falk et al. 2006; Lake et al. 2007). At the ecosystems-level, restoration ecology has chiefly been influenced by research on the importance of natural disturbance, energy flow, and nutrient cycles (Naeem 2006; Kaushal et al. 2008). Together these bodies of knowledge have shaped the emergence of ecosystem restoration as a science with a particular influence played by at least three broad categories of theory, concepts, and data: (1) equilibrium dynamics and state changes; (2) scale and context dependency; and (3) diversity and heterogeneity. However, what is being done on the ground to restore ecosystems-ecosystem restoration in practice-does not necessarily reflect an acceptance of these concepts. Furthermore, some concepts have been adopted in a simplified form despite little evidence to support the way in which they are applied. Finally, even though restoration is fundamentally a human-directed enterprise, theoretical, and empirical treatment of these concepts with humans as integral components of ecosystems is seriously underdeveloped (Palmer et al. 2004).
Equilibrium Dynamics, Thresholds, and State Changes

The existence of definable states or conditions that systems exhibit has formed the basis of a great deal of theoretical work in ecology. The idea is that populations, communities, and entire systems might move away from a recognizable 'normal' state following a disturbance but would 'tend' back toward the state after some period of recovery time (Pimm 1991). The classic descriptions of population growth given limiting resources (e.g. logistic growth) assumed that there was some carrying capacity $(\mathrm{k})$ or "equilibrium" population level for a given habitat at a given point in time; deviations from $\mathrm{k}$ suggest the resource base may have changed and/or the population is not under densitydependent control.

The equilibrium concept has also been applied extensively by community ecologists. For example, island biogeographic theory predicts an equilibrium number of species in a habitat as a function of the immigration and extinction rate (MacArthur and Wilson 1967). Succession theory, which has played a major role in plant community ecology (and in terrestrial restoration), also assumes directional change toward a single equilibrium point (Suding and Gross 2006). A great deal of work on ecosystem stability and persistence assumes equilibrium dynamics (Loreau and Behera 1999), as do many basic ecosystem models for nutrient cycling (Scoones and Toulmin 1998). In sum, a large amount of ecological theory has been dominated by deterministic perspectives in which internal feedbacks were assumed to keep systems in balance.

The possibility that multiple, stable states may exist is a concept that has been around for decades (e.g. Lewontin 1969); however, it has re-emerged as a topic of great interest because of concerns over ecosystems crossing "ecological thresholds" that result in abrupt state shifts that are difficult to reverse (Carpenter et al. 1999). Some scientists argue that most ecological systems have multiple stable states which they tend toward under different conditions ('stable point attractors') and these are separated by unstable transient thresholds (sensu Walker and Meyers 2004). Under this assumption, the key to restoration and management is not about keeping the system in the same state - this is not possible. Instead, the key is identifying what factors initiate changes that shift an ecosystem toward a state that is unacceptable (a societal decision), and then controlling those factors or enhancing ecosystem resilience to changes in those factors (Walker et al. 2004). Not all ecosystems exhibit threshold changes, but for those that do, the question becomes: can we identify a threshold before it is crossed? Answering this question is a central goal in the study of coupled human-ecological systems. While we currently have no theory or tools for predicting if and when a system nears a threshold, there is a great deal of work 
underway, including a joint effort by the Santa Fe Institute and the Resilience Alliance to build an empirical database on regime shifts in ecosystems and coupled socio-ecological systems (Walker and Meyers 2004).

Relevance to Restoration The equilibrium view is firmly entrenched in ecosystem restoration in theory and practice as evidenced by the dominant use of reference sites or reference conditions to set restoration targets (e.g. Steyer et al. 2003). In some cases, these targets relate to former conditions such as historic population levels and community composition, while in many other cases nearby sites that are considered undisturbed serve as the reference (White and Walker 1997). A recent, high-profile example relates to the search for an ideal reference channel form for use in guiding stream restoration efforts (Montgomery 2008; Bain et al. 2008). The presence of agriculturally derived, legacy sediment deposits in some river floodplains of the mid-Atlantic US (Walter and Merritts 2008) has stimulated interest in 'removing' these sediments in order to restore stream channels back to their pre-settlement 'natural' (reference) condition (Gutshall 2004). This is despite the massive regional changes in land-use and water infrastructure that act as on-going 'disturbance' events and may mean that historic fluvial forms can't address contemporary riparian restoration issues (Bain et al. 2008). Instead, channel morphology in many of these regions may be in a perpetual state of disequilibrium as it continues to adjust to changes in run-off and sediment delivery. Thus, use of some 'ideal template' as a reference to guide restoration projects may lead to failures or overengineered structures (Fig. 2).

The preoccupation with fixed reference sites ignores a great deal of ecological theory that has come along over the last $30+$ years as ecologists began expressing great discomfort with the equilibrium concept (Parker and Wiens 2005). Problems include: application of the concept requires that there is some form of self-regulation that governs system dynamics; the concept typically does not apply at the small spatial and temporal scales in which most ecologists work; and the concept minimizes the importance of history, disturbance, and stochastic factors (DeAngelis and Waterhouse 1987; Wu and Loucks 1995). There is usually very little understanding of what, if any, internal regulating processes control the state of an ecosystem in need of restoration (Mayer and Rietkerk 2004). In fact, there is growing evidence that regulating processes may be 'external' to the nonhuman ecological system and reside at the level of the socio-ecological system-i.e. the ecosystem in its human context including its anthropogenic stressors and the feedbacks between ecosystem state and the sociopolitical management of its stressors (Liu et al. 2007).
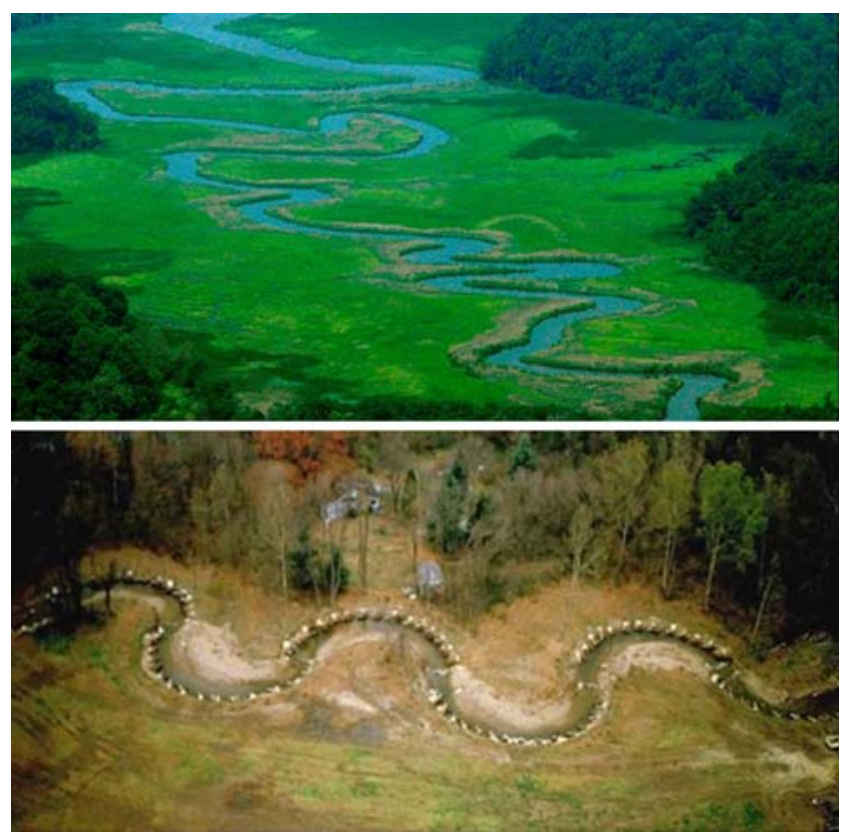

Fig. 2 Over the last decade, one of the most common approaches used to design river restoration projects is based on the assumption that constructing a channel whose form is similar to a historic or leastdisturbed reference site will result in a stable stream. In the eastern USA, the reference condition is often assumed to be a highly sinuous channel such as the one shown in the top (photo by A. Eckert). This has led to extensive channel manipulation and sculpting of the landscape as shown in the bottom photo (photo by S. Smith); this stream restoration effort was a dramatic failure (Smith and Prestegaard 2005)

With respect to spatial extent, restoration efforts typically involve taking only a small 'piece' of an ecosystem and assuming that given suitable treatments, it can recover to "equilibrium" (reference level) conditions despite its landscape/watershed context. Rarely are restoration actions taken over large temporal and spatial scales. Even if the desire is to restore an entire estuary, actions that are informed by ecological theory are typically implemented at the scales of hundreds of meters of shoreline, single oyster reefs, and sections of tributaries (Luckenbach et al. 1999; Zedler 2000; Bernhardt et al. 2005). Yet ecosystem processes like nutrient cycling, that involve the movement of many constituents, occur at much larger scales and in some cases over entire watersheds.

The important role that disturbances such as hurricanes and floods play in maintaining the ecological health of coastal wetlands, estuaries, streams, and river floodplains is extensively documented and yet countless restoration efforts attempt to minimize or eliminate geomorphic change in these ecosystems (Simenstad et al. 2006). While this is understandable if people and homes are at risk, efforts to suppress change in a system once it is restored are common even in areas where such risks are not an issue. For example, many stream restorations use a method called 'natural channel 
design' (Rosgen 1996) which is based on estimating channel dimensions that will prevent erosion or deposition of sediment even if the stream is on undeveloped land with ample room for channel migration (Kondolf 2006).

In contrast to viewing restoration goals as static endpoints, Suding and Gross (2006) have argued that stochastic events such as disturbances could be combined with deterministic processes to design restoration and monitoring programs if the focus is on variation in trajectories of recovery. In fact, in severely degraded ecosystems Zedler (2000) has argued it is particularly important to consider many possible pathways to restoration because assuming an ecosystem can be returned to some historical or reference condition may divert attention from the need to identify internal feedbacks that are operating to keep the system in a degraded state. Restoration may require novel pathways because the dynamics of the degraded system may be very different from the desired state and the recovery trajectory can be quite different from the collapse trajectory (Fig. 3) (Hobbs and Norton 1996; Suding et al. 2004; Chambers and Linnerooth 2001; Duarte and Conley 2008).

\section{Scale and Context Dependency of Ecological Response}

The dynamics of individual species, the composition of entire assemblages, and the rates and form of ecosystem processes vary spatially not only because of local conditions but because of the movement of individuals and the flux of materials. The arrangement of habitats across the landscape,

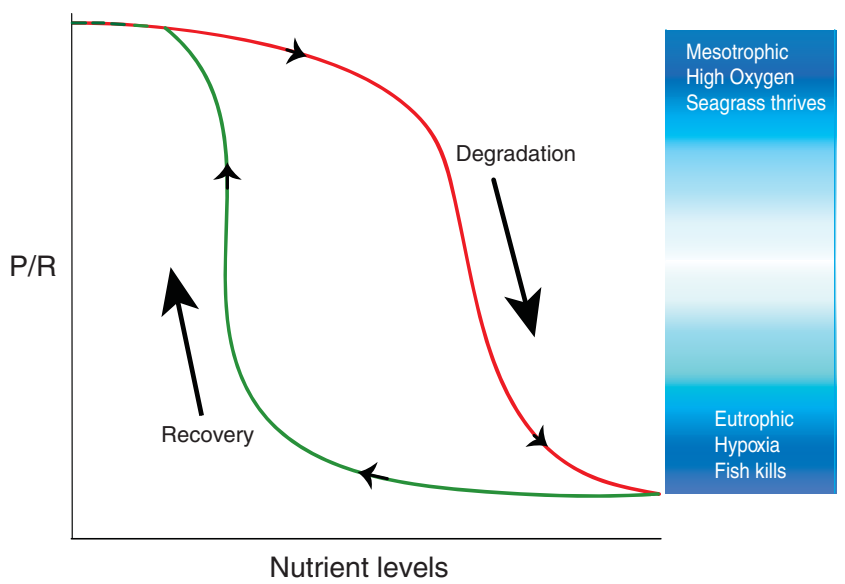

Fig. 3 Degradation of a coastal ecosystem due to excessive levels of nutrients is represented here as a decline in the system production/ respiration ratio $(\mathrm{P} / \mathrm{R})$. The system is stressed with higher and higher levels of nutrients until it reaches some threshold point at which oxygen plummets and kill-offs begin. The path to degradation is however not necessarily the same path it will take as it is restored; nutrient levels may need to be reduced far below the level at which the system-level degradation was first apparent in order for the system to recover spatial population structure, dispersal abilities, and the magnitude and direction of material flows all act to determine ecological patterns and processes, and so it is not surprising that ecologists have abundant evidence that species may perform differently in different environmentsi.e. performance is context-dependent (Power et al. 1996). Environmental conditions determine if a species is physiologically capable of living in a particular region; subtle, within-region differences in these conditions along with biotic interactions may enhance the survival and reproduction of a species (i.e. its performance). These 'optimal patches' may serve as sources of colonists to other patches while suboptimal patches may act at sinks (high mortality); the degree of dispersal among these regions may determine population sizes and risk of extinction (Mouquet and Loreau 2003; Hanski and Gaggiotti 2004). For some species, there are critical thresholds of patch connectivity needed to ensure a supply of colonists (Turner and Gardner 1991).

Spatial and temporal environmental heterogeneity also influence the functional role species play in ecosystems (Wellnitz and Poff 2001). For example, both facultative feeding and changes in species interactions are known to be associated with changes in flow in both marine and freshwater systems (Cardinale et al. 2002; Cardinale and Palmer 2002; Hentschel and Larson 2005). This contextdependency of performance or interaction strength can influence ecosystem-level processes such as production and resource utilization (Cardinale et al. 2001; Stachowicz et al. 2007). Changes in such key processes can have cascading effects on nearby ecosystems, particularly in river networks where the movement of materials can effectively link very distant ecosystems (e.g. headwater streams to coastal marshes). For this reason, ecologists have increasingly focused research on broader spatial contexts and multi-scale processes. For example, some ecosystems receive substantial inputs of nutrients or organisms that act as ecological subsidies (Palumbi 2003). Nakano and Murakami (2001) showed that across-habitat prey flux accounted for $25.6 \%$ and $44 \%$ of the total annual energy budget of bird and fish assemblages in a Japanese stream. Subsidies such as these have been extensively studied both theoretically and empirically (e.g. Polis and Hurd 1996), but there are also unwanted forms of 'ecological commerce', particularly in the case of pollutants or other inputs that arise from human activities (Palumbi 2003; Palmer et al. 2004). Subsidies whether positive or negative, can exert tremendous control over ecological systems and for watersheds. Because the delivery of subsidies may be controlled by the dendritic network configuration of river channels the study of material fluxes and the persistence of species can be complex (Grant et al. 2007).

Relevance to Restoration Given the potentially large spatial variability in a species performance in heterogeneous 
environments, the selection of restoration sites is critical. The position on the landscape or seascape may mean the difference between success and failure of newly established populations. Just as theory predicts there may be an optimal number and size of marine reserves that must be spatially arranged to maximize the persistence of a species (McCarthy et al. 2005), optimization of the size and position of a restoration project is important (Palmer et al. 1997; Craig et al. 2008). Smith and Lamp (2008) found that as urbanization proceeds in a watershed, insect taxa unique to headwater streams were at the greatest risk of extirpation and the authors suggest that once taxa are lost, the supply of dispersing adults from other headwaters may limit the success of headwater restoration projects. Unfortunately, we know very little about dispersal dynamics of freshwater and coastal species such as their maximum dispersal distance or preferred dispersal routes because faunal movements are so difficult to measure. It is therefore not surprising that decisions on the spacing and size of restoration efforts have only generally considered the potential for dispersal limitation (Lake et al. 2007).

Site selection for restoration projects is mostly opportunity based and not informed by factors such as metapopulation structure, ecological subsidies, or health of adjacent waterways. In fact, despite common acknowledgement among managers that watershed and landscape context are critical to restoration, only a small fraction of stream and river restoration projects throughout the USA have been initiated because of a broader river or watershed management plan (Bernhardt et al. 2007). For most projects, sites are selected based on land availability even though this does little to ensure project success, and in some cases results in the selection of sites that are clearly suboptimal. For example, restoration efforts to remove flow barriers and enhance the migration of anadromous fish in watersheds that are impaired, have contaminated sediments behind the barrier, or have non-native species that will extend their range must be viewed as foolhardy or, at best, as a trade-off (Stanley and Doyle 2003). While dispersal (migration) is important, the most basic elements of survival given the local environmental context can not be ignored.

Problems stemming from opportunity-based site selection are often compounded by a stove-piping approach to environmental management when it comes to agencies and funders that focus programs on specific habitat types not broad regions. Site selection and design of most restoration projects are done in a compartmentalized fashion such that tidal marshes, freshwater tributaries, and parcels of land are restored or conserved independently of their link to one another. Rarely are efforts coordinated at whole watershed scales to maximize environmental benefits even though the value of targeted watershed approaches is being increasingly recommended. Political pressure and jurisdictional issues remain huge obstacles to implementing the scale of efforts restoration scientists' advise. Coordinated large-scale restoration is also impeded because of a mismatch in how freshwater vs. marine ecosystems are assessed and by lack of data on factors that link these ecosystems. For example, in the Chesapeake Bay region, measures of stream health for prioritizing restoration efforts are most often based on invertebrate diversity or loss of sensitive insect species (EPA 2006), yet assessments in large coastal rivers and tidal creeks largely focus on dissolved nitrogen and suspended sediment (e.g. CBP 2007). While diversity is undoubtedly important for stream ecosystems, it tells one little about the ability of a stream to reduce the downstream flux of nitrogen or sediment. There is no statistically significant relationship between insect diversity and stream nitrogen levels unless nitrogen concentrations reach levels rarely seen (EPA 2006), and the relationship between suspended sediment and insect diversity are only generally known (Berry et al. 2003; Matthaei et al. 2006).

This myopia or 'my habitat' focus flies in the face of widespread acknowledgement of the importance of watershed perspectives in management plans and agency documents. In fact, the extent to which the spatial scale (area) of a restoration effort influences restoration success has not been extensively studied even though the failure of some projects has been attributed, at least in part, to the size of the project (Ehrenfeld and Toth 1997; Hughes et al. 2005). In some cases, the area of restored habitat is simply too small compared to the size of nearby degraded habitat or the flux of water from upstream degraded habitat overwhelms efforts. There are numerous examples of stream and river restoration projects designed to reduce erosion but I know of no examples in which the net flux of sediment reaching tidal waters has been shown to be reduced through a stream restoration project. Identifying hotspots within watersheds that act as net sources or sinks of sediments would allow one to target small restoration sites, but such strategic, science-based selection of sites for restoration is simply not occurring today. Furthermore, it is worth questioning the assumption that all sediment movements are detrimental. Actually, sediment flux is a natural geomorphic process that is ecologically very important and further, reducing sediment flux below historic levels would be atypical with respect to how coastal receiving ecosystems evolved (Carter and Woodroffe 1994; Florsheim et al. 2008).

In sum, ecological understanding of the importance of material exchanges, spatial variability, and multi-scale interactions is significant but has had little influence on restoration in practice; it is not that the science is buried but that it is simply not being used. I briefly discuss sociopolitical issues that may be driving this later. 
Diversity, Heterogeneity, and the Maintenance of Species Assemblages

The issue of what promotes diversity and why it matters ecologically has probably received more attention theoretically and empirically than any other issue in ecological science. Genetic diversity, species diversity, and habitat diversity have all been extensively studied. Genetic diversity allows organisms to adapt to environmental variation and reduces inbreeding depression thus contributing to the maintenance of populations (Lowe et al. 2004). Entire books have been written on this important topic so the reader can look elsewhere for an overview of theory and empirical work on the importance of genetic diversity.

Ecologists have argued that a primary reason that species diversity is important is because it may contribute to community stability and ecosystem function (Naeem et al. 1994; Tilman et al. 1996). The link between diversity and ecosystem function has been hotly debated, particularly over whether it is driven by one or a few species or if it is even a statistical artifact (Hooper et al. 2005). The current view on the link is that function probably does decline as species are lost but the reasons for this vary dramatically among systems and the magnitude of the effect is determined by the identity of the species lost (Cardinale et al. 2006). Thus, increasing attention has focused on the contribution of individual species to ecosystem functions, with the most focus on the role of species in rates of primary productivity. A meta-analysis of work in eight different European grasslands suggests that different species have a disproportionate impact on different functions so that maintenance of multi-functional ecosystems may require maintenance of high species diversity (Hector and Bagchi 2007). If both functional diversity and response diversity within functional groups are high, an ecosystem may exhibit a great deal of resilience in the face of environmental changes (Elmqvist et al. 2003).

Stability of ecosystem function does not mean that the species composition never changes. Whether or not more diverse ecosystems are also more stable in terms of exhibiting little change in species composition over time is debatable (McCann 2000). Current thinking is that community stability may be strongly associated with diversity because as long as species are only weakly interacting, diversity buffers communities from the impacts of a disturbance as species responses to the disturbance will vary. But the nature of the relationship between diversity and stability is complex and varies with system and environmental conditions (Shurin et al. 2007). In some settings or under some conditions, low diversity is associated with high levels of stability, not vice versa. The links between diversity and stability are difficult to study because temporal species turnover may be linked to environmental stability and seasonality, not diversity, and these can be hard to separate (Keitt 2008).

Working on the assumption that diversity is important to functionality and potentially to stability, ecologists have sought to understand what promotes diversity. Theoretical and empirical work on species diversity dates to the early days of ecological icons such as Hutchinson (1959) and MacArthur and MacArthur (1961). Of particular interest is the large body of ecological research on the link between species diversity and habitat heterogeneity (Tews et al. 2004) because this research has played an important role in the theory and practice of restoration (Palmer et al. 1997). In fact, central to many restoration efforts is the assumption that rehabilitation of physical habitat diversity will lead to the restoration of biological communities (Brown 2003; Spanhoff and Arle 2007).

The term heterogeneity has been used very loosely by ecologists - it may refer to habitat complexity (technically the spatial arrangement of patches), habitat diversity (the number of types of habitats in an area), and sometimes even environmental variability within a habitat over time ( $\mathrm{Li}$ and Reynolds 1995). Species diversity has been shown to increase with habitat heterogeneity for a variety of species ranging from birds and mammals to insects and demersal fish (MacArthur and MacArthur 1961; Murdoch et al. 1972; Kaiser et al. 1999). The mechanisms are numerous and not necessarily mutually exclusive: habitat heterogeneity may provide more physical space, refuge, resource availability, and open niches for members of a community, thus promoting diversity. A great deal of work has focused on the role of niche fractionation in promoting diversity and the role of refuges in time and space minimizing competitive exclusion and mediating predator-prey interactions (Grabowski 2004; Willis et al. 2005).

Relevance to Restoration The goals and approaches of many restoration efforts reflect the deeply held view that diversity is important - whether this is genetic diversity, habitat (patch) diversity, or species diversity. Restoration efforts are also largely based on the view that it is native species and habitats as well as wild genotypes that are desirable. Of course, this begs the questions, "desirable to whom?" and "what is the definition of native?" If ecosystems continue to perform functions that support valued ecosystem services such as the provision of clean water, perhaps the presence of non-natives is irrelevant. Dramatic events in which native species are lost due to the invasion of a non-native tend to be well remembered even though they are not necessarily very common relative to the number of non-natives that reach an area unnoticed. The use of non-native species in restoration efforts is not new and some have even argued that now is the time to consider moving species beyond their native range as a pre-emptive 
measure for species unable to disperse or adapt fast enough to keep up with climate change (Hoegh-Guldberg et al. 2008)

Restoration efforts for fisheries and wildlife populations, particularly endangered or threatened species, routinely consider a myriad of genetic issues and, in fact, the goal is often to enhance genetic diversity with the hope of reducing the risk of extinction (Machado-Schiaffino et al. 2007). But aside from valued fisheries or threatened species, there has been only scant research on the role of genetics in restoration success and this is mostly on plants. Travis et al. (2002) found that Spartina alterniflora that naturally colonized restored marshes had levels of genetic diversity as high or higher than reference sites. However, when plants are collected elsewhere and brought to a site, genetic diversity is not always as desired as was the case for eelgrass (Williams 2001). In the last decade, increasing attention has been given to the genetic composition of individual plants or animals that are brought to a restoration site, but the application of genetics theory to restoration is still in its infancy.

Interest in establishing diverse assemblages of species by restoration ecologists stems from the tenet that an ecosystem's ability to withstand disturbances (i.e. be more stable) may be central to its long term survival following restoration, and that this ability is enhanced when species diversity, and thus functional redundancy, is high (Lake et al. 2007). This suggests that a restoration practitioner needs to carefully evaluate community level attributes and those factors that promote species diversity. Yet, the historical fishery-science approach of managing single stocks as well as societal preferences for certain iconic species have resulted in a huge number of freshwater and marine restoration efforts focused on only one or a few species (e.g. species of migratory salmon in the Pacific Northwest and oysters in the mid-Atlantic US). Despite their costs, these projects are common even where there is little evidence that efforts have resulted in measurable improvements (e.g. for salmon, Katz et al. 2007; for Eastern oysters, Mann and Powell 2007). As I elaborate on later, such projects are far more successful when they move away from structural fixes and focus on process-based restoration and identification of those factors limiting recovery of a fishery (e.g. as in Bottom et al. 2005).

When we turn our attention away from restoration of commercially important fisheries, species diversity as a stated restoration goal is actually quite common and is often assumed to be associated with increasing habitat heterogeneity (Palmer et al. 1997; Larkin et al. 2006). For example, an increase in the size and abundance of transient fish over oyster reefs in the Chesapeake Bay has been assumed to be due to an increase in the structural complexity of the habitat (Harding and Mann 2001). Topographic heterogeneity of freshwater wetlands has been implicated as critical to restoration of a variety of wetland species because small variations in elevation can shift hydrologic conditions and biotic responses (Vivian-Smith 1997). In tidal marshes, adding topographic heterogeneity in the form of multiple vegetative zones and mixtures of pools and creeks is believed to enhance restoration of invertebrates and fish (Larkin et al. 2008). Finally, a number of studies on sea grass ecosystems have suggested that the diversity of epifaunal communities increases as structural complexity of sea grass increases so long as the total habitat area is held constant (Sirota and Hovel 2006). While direct tests in an actual sea grass restoration project have not yet been published, there is a growing consensus that the arrangement of sea grass in space is critical (Bostrom et al. 2006).

These studies and many others suggest that the focus on habitat heterogeneity that has occupied ecologists for so long has largely been adopted in the field of restoration ecology. In some aquatic habitats, efforts to enhance physical habitat heterogeneity are so pervasive that hundreds of millions of dollars are spent annually on just the habitat aspect of the restoration process despite lack of evidence it works. For example, restoration of many streams has largely consisted of placing and sculpting in-stream structures in the name of 'habitat improvements', yet studies to date have not routinely confirmed that increasing habitat heterogeneity results in increasing species diversity or even restoration of individual taxa (Roni et al. 2002; Lepori et al. 2005). For example, stream fish are widely assumed to respond to an increase of in-stream habitat structures such a log jams, boulders, rock-filled gabions, and gravel, without definitive evidence this is true (Pretty et al. 2003; although see Schneider and Winemiller 2008). If increases in fish abundance are actually observed, they may be due as much to aggregation around the structures as to recovery of populations (i.e. successful reproduction and recruitment).

Despite the widespread focus on maximizing habitat heterogeneity and the suggestion that for wetlands and tidal marshes this may actually contribute to more diverse assemblages, it is not clear whether heterogeneity per se (i.e. habitat diversity and spatial arrangement of patch types) is what promoted restoration or it is just the presence of critical habitats or an increase in area (MacNally and Watson 2006). Just as there are keystone species in some ecosystems, there may be keystone habitats (Davidar et al. 2001) that are critical to the success (long-term persistence) of a restoration effort; such habitats need much more study by ecologists. Some of these habitats are the direct result of keystone species that act as ecosystem engineers. This is particularly obvious in aquatic systems in which oysters, coral, or beaver create complex habitat over extensive areas. In fact, these species are being increasingly used as 'tools' to enhance or stimulate restoration of bays, estuaries and wetlands (Bunt et al. 1993; Gorshkov et al. 1999; Nelson et al. 2004). However, it is not clear if desirable 
ecosystem-level effects that such keystone species produce are the result of increased habitat heterogeneity or other factors. Furthermore, we do not yet know if there are thresholds of habitat area and connectivity that must be restored to sustain populations and communities. Certainly, for stream restoration projects, the lack of any evidence to justify manipulations of habitat heterogeneity could be a threshold issue since most stream restoration projects are small in scope (Bernhardt et al. 2005).

\section{Restoration Reform}

What I have attempted to do is illustrate the ways in which ecological theory and concepts could inform the practice of restoration and the limitations of that to date. I have provided examples in which well-accepted scientific findings and theory are not being used, where theory has been adopted to the point of almost being dogma even though there is scant scientific evidence to support its use in a restoration context, and where we simply lack enough data or theory to effectively inform restoration (Table 1). As restoration science and practice develop, it is imperative that we examine and reexamine the assumptions and scientific evidence (or lack thereof) that underlie restoration efforts.

In some cases, managers simply need to be made aware of the latest science while in other cases scientists need to test methods that have not been scientifically evaluated but are widely used in restoration projects. Unless we can move ecological theory into more predictive modes, the most practitioners can do is apply basic ecological concepts in the general ways I outline below in "science in need of application". Until these concepts are developed into relationships with predictive power, scientists must stress the importance of using the least interventionist and least expensive restoration approaches and then, only after weighing the potential risks vs potential benefits. There is also a great deal of new research that is critical if science is to play a useful role in restoring coastal watersheds and I outline some of these below in "applications in need of science". For scientists to accomplish these tasks, routine tracking of methods and concomitant outcomes in restoration projects across diverse environmental and social contexts is required. Documenting failures is as important as successes and will accelerate the science and practice of ecological restoration.

Table 1 Many scientifically well-accepted and fundamental ecological principles are under-utilized in restoration efforts while simultaneously some restoration practices in common use have not been adequately tested by the scientific community. The list is meant to be illustrative, not exhaustive. Examples of some of the most obvious consequences are also provided

Implications

Under-utilized principles

Ecosystems often exhibit nonlinear, nonequilibrium dynamics

Processes critical to restoration typically reside at the level of the socioecological system

Regional scale processes often swamp local processes

Ecological systems are spatially structured

The dynamic character of natural systems is important to their health

Multiple, interactive factors control ecological systems

The exchange of material across systems (ecological subsidies) is critical to the health of many ecosystems

\section{Inadequately tested practices}

Physical habitat heterogeneity promotes restoration of biological diversity

The beneficial effects of many small restoration projects are additive; recovery will occur steadily as stressors are removed and sites restored

Created and restored ecosystems support rates of ecological processes similar to natural systems

Streambank stabilization projects result in a net decrease in sediment flux to coastal waters
Can not assume an ecosystem will return to a former state or reference condition or that restoration trajectory is similar to degradation path

Manipulating just the physical environment will not usually lead to sustainable environmental change

Unlikely that small areas embedded in a larger, degraded system can be restored in isolation

Spatial context of a project is fundamental to restoration success; critical thresholds of connectivity among restored sites may exist

Fixed structures typically fail or lead to a degradation of ecological processes and biota

Single-fix approaches (e.g., restore habitat, re-stock species) rarely work

Fundamental changes in the natural movement of material (propagules, energy, organic matter) will interfere with restoration

Diverts attention away from other factors that may be more important to restoring diversity; costly

Many small projects may be easier to fund and implement but may not be as effective as larger projects; public expectations may go unmet

If processes are not supported, environmental benefits of project will be limited

Projects are very costly, may have little impact on sediment flux but negative impact on stream biota 
Science in Need of Application: Well-accepted Concepts not being used

1. Focus on processes and limiting factors not structures or single species.

Roni et al. (2002) emphasize the need to shift the focus of river and estuarine restoration from structural interventions to efforts to restore hydrologic, geologic (sediment delivery and routing), and riparian processes. Only once these are restored should in-stream habitat enhancement be used. The lack of focus on the restoration of processes is the single most important scientific concept that is currently missing from restoration efforts. Partly this is a result of how difficult it is to translate general theory on ecosystem processes to specific ecosystems and species assemblages without a great deal of life history and system-level information. But that can not explain the widespread practice of applying structural approaches to restore ecological communities rather than process-based approaches. Examples of process-based restoration include restoration of hydrologic flow paths and flow regimes that enhance biogeochemical and physical processes to help purify water moving into streams and estuaries. This could be in lieu of using existing funds to replant oysters in polluted bays or in lieu of re-configuring coastal streams using large boulders to keep channels fixed in place, or in lieu of restoring salmon habitat on river segments without removing upstream barriers. As a final example, many wetland restoration and creation projects have the stated objective of restoring hydrological processes, but few actually measure processes such as denitrification and carbon sequestration (Cole 2006; Euliss et al. 2008). Instead, the assumption is typically made that structural attributes such as those in the widely used Hydrogeomorphic Approach to wetland assessment are adequate surrogates for function (Rheinhardt et al. 1997).

\section{Add ecological insurance to all projects}

The science of restoration is a very young discipline, yet the need for it is already urgent. This means that projects will take place before we have fully tested many theories. To maximize environmental benefits, it makes sense to be conservative when it comes to using high risk approaches and to be liberal in incorporating options into designs that may provide benefits but certainly won't do harm. For example, the probability of ecological damage due to the intentional introduction of a non-native species may be small but the consequences dire and stream restoration projects that are highly interventionist potentially result in more harm than good; both restoration approaches should only be done with great caution. In contrast, logic suggests that efforts to restore the full suite of native species to a site are wise even though we do not fully understand the link between diversity, ecosystem function, and ecosystem stability. High diversity may serve as a kind of 'insurance' against ecosystem collapse, if it buffers change in functional composition of the community. Furthermore, communities with high diversity may be less susceptible to invasions by 'weedy' non-native species (Shurin 2000). Other types of ecological insurance include developing science-based prioritization and sitescreening tools that can be used to manage the risk of ecological failure of a particular project (Craig et al. 2008). These tools might be based on information at the site level (e.g. percent invasive cover, water quality), the landscape (e.g. adjacent land use, susceptibility to sea level rise, or hydrologic regime), or on knowledge of stochastic events (e.g. probability of natural or anthropogenic disturbances).

3. Identify a probabilistic range of possible outcomes instead of a reference condition

Incorporating nonequilibrium dynamics into restoration planning suggests that many pathways are likely possible and may depend on restoration actions (Duarte and Conley 2008) and thus, it is important for restoration "targets" to be based on an array of possible outcomes or states. As Hughes et al. (2005) have argued, using reference systems can give a false sense of predictability of ecological outcomes. Rather than selecting reference 'endpoints', a desired trajectory should be defined that takes into account a range of values for key system attributes that are inherently variable; e.g. ranges of flow and sediment inputs, variability in the location and number of habitat types, and changes in the species composition of assemblages through time and space (Hughes et al. 2005).

In an excellent paper, Poole et al. (2004) argue that rather than setting water quality standards (set levels) managers should work toward setting regime standards which describe a distribution of conditions over space and time that is desired. They argue that the concept of traditional standards arose in response to concerns over toxic materials that cause lethal conditions once they reach some simple threshold. However, nonpoint source problems dominate restoration today and these problems vary tremendously over time and space. Setting a single threshold encourages "homogenization of naturally diverse and dynamic systems" (Poole et al. 2004; page 157). Furthermore, it assumes that systems are unresponsive to gradually increasing stressors until some break point is reached and that ecosystems can not maintain their health when the threshold is temporarily exceeded or is exceeded in some patches but not others. If a suite of reference sites that span a gradient of stress can be identified, this can help to identify the suite of potential restoration trajectories.

4. Expand the spatial scale of restoration implementation 
The vast majority of restoration projects are too small and too isolated. Whole watershed and whole-estuary perspectives are crucial because the spatial arrangement of tributaries and the connectivity of suitable habitat may determine survival and dispersal potential. The announcement that "tributary strategies" would be developed for the Chesapeake Bay region that would coordinate efforts as diverse as riparian restoration, agricultural best management practices, stormwater run-off control, and wetland restoration across watershed scales was met with great excitement in the mid-1990s. However, in practice, the strategies have not led to such coordination-different agencies are responsible for different efforts, do not share common databases, and state and county jurisdictional boundaries not watershed boundaries, typically determine the scope and location of projects. Thus, for example, the density of stream restoration projects by county in Maryland (Hassett et al. 2005) bears no resemblance to the distribution of impaired waters or waterways (MDE 2004). The need to expand scales is not limited to a landward focus; estuarine restoration efforts may also rely on knowledge of coastal ocean processes. For example, Cloern et al. (2007) found that climate-driven changes across the Pacific can influence the efficiency with which landderived nutrients are converted into algal biomass in the San Francisco Bay estuary.

5. Apply a hierarchical approach to prioritize sites and choose restoration method

Science-based prioritization schemes that are consistent with specific goals should be developed to identify sites most in need of restoration and then, as necessary, take social and political issues into consideration in selecting from among the top priority sites. Currently in most settings the social and political issues take precedence over science. While we are far from identifying the relative importance each of multiple factors play in limiting the health of ecosystems, we can apply a logical, data-driven approach to choose among various restoration methods and to prioritize sites for restoration. As we build up a database on processbased responses to restoration treatments and combine this with data on a range of project characteristics, we can develop useful relationships between observable characteristics and probabilities of outcomes.

Prior work has shown that analysis of location characteristics conducted with GIS tools and available data can provide strong indicators of site-specific conditions (Brooks et al. 2004; Weller et al. 2007) that may determine probability of success given a particular method. For example, the level of watershed modification, adjacent land use, susceptibility to sea level rise, or hydrographic setting may be critical to project outcome. Restoration of wetlands in regions highly likely to be underwater in 25 years due to climate change is obviously not a wise investment. Similarly, habitat restoration in a tributary or coastal zone that is undergoing rapid urbanization makes little sense unless stormwater management is first implemented.

Applications in Need of Science: The Practice of Restoration Demands More Science

1. Test theories most relevant to the practice of restoration

The scientific community of today understands that it is critical they do research of societal importance; however, too often this research contributes little to actually addressing real problems because of a gap between ideas and implementation (Sarewitz and Pielke 2007). There are many interesting research questions that could expand fundamental knowledge on coastal waters and their tributaries, but given the crisis our waters are in today, top priority should be given to research whose results can be immediately implemented. For example, research results showing that protection of wide riparian buffers around urban streams improve water quality is interesting but of little use in most cities where waterways are already developed and almost certainly not destined for infrastructure removal and costly re-greening. On the other hand, research showing that in-stream wetlands used to manage stormwater improve water quality may be of use immediately. So scientists could ask what restoration "tools" are available and likely to be publicly acceptable and how can these be used to enhance ecological restoration? This is not meant to squelch inquiry and discovery-focused applied research as I am describing should be complemented with basic research — but to accelerate the pace of restoration science.

2. Determine if physical manipulations can be used to manage ecological processes

Previously I have argued that the historical roots of restoration science in aquatic ecosystems can be traced to engineering disciplines and grew largely out of an emphasis on flood control (Palmer and Bernhardt 2006). The focus was on designing river channels or shorelines to efficiently route water or wave energy away from or toward specific areas with little regard for the function of ecosystems. Over time, hydrogeomorphic approaches to restoration emerged in which the aim was to imitate natural alluvial systems using softer engineering approaches that focus on the dynamics of sediment and water movement. However, approaches were still largely structural in nature including for example reshaping of channels and placement of structures to alter sediment transport. Only recently have ecologists entered the scene and begun pushing for a focus on restoration of ecological processes and the need to understand the 
ecological consequences of hydrogeomorphic manipulations that are commonly used but poorly studied. We have very little understanding of how to influence ecological processes using the tools that practitioners have available-i.e. can we enhance the flux of propagules to isolated bays using constructed channels (dispersal corridors)? Can we manipulate physical habitat to reduce the net flux of nitrogen to coastal waters through the construction and enhancement of denitrifying areas across a watershed (Brush 2008)? Does addition of physical structure enhance secondary production of fish or just aggregate them? Answering these questions requires quantitative monitoring of processes pre- and postrestoration which at present, is extremely rare (but see Fellows et al. 2006; Roberts et al. 2008).

3. Identify feedbacks between social and ecological systems that act to constrain science-based restoration

The most commonly cited reasons that science is not being used are socio-political and legal. An argument often heard is that the interests of stakeholders and the bureaucratic structures of regulatory and management agencies inhibit the implementation of truly science-informed restoration. Even if this is true, it does not mean that scientists have no role to play in overcoming the obstacles. The rapidly expanding literature on ecosystem based management (Leslie and McLeod 2007) suggests that new scholarship is needed to understand watersheds as socioecosystems-linked social and ecological systems in which there are complex, and often nonlinear, interactions between humans and the natural world (Walker et al. 2002) that determine management and restoration outcomes as well as social willingness to change (Berkes et al. 2003).

Many of the same principles we have historically applied in ecology may be applicable to the social and political systems that are linked to the very ecological systems we study. Are more diverse and flexible governing structures better able to respond to changes in the environment in ways that enhance the mutual sustainability of people and nature? For example, presently in the USA, many aquatic ecosystems are protected by a number of regulations under the auspices of the Clean Water Act whose enforcement is largely left to individual states. However, because the environment is changing rapidly and our scientific understanding of it is also changing rapidly, why not apply a combination of scenario-building, ecological forecasting, in addition to regulations to manage our waterways? If researchers can identify biophysical-social interactions that are critical to balancing preservation, restoration, and human use of water resources, this could enhance scenario and forecasting exercises. If researchers can identify the scale at which these interactions occur, then the scale at which policy changes need to be implemented becomes clearer (Liu et al. 2007). To measure the efficacy of these policies requires the identification of indicators that can be used to assess desired ecological and social functions. Can indicators also be developed to assess the resilience of these functions? Reforming graduate education to train students to address such questions is critical if we have any hope of answering such questions.

4. Determine how and when we can replace ecosystem functions using created ecosystems

Over the last several decades, the notion that ecosystems can be created has emerged and it has now gone wildthousands of projects labeled as wetland creation occur every year, tidal marsh creation is now appearing, and even the possibility of stream creation has been raised in the most recent revision of the compensatory mitigation regulations in the USA (Federal Register 2008). The motive for creation projects is to replace or mitigate for aquatic resources that are lost and the social pressure for creation projects is clearly quite high. Creation projects are often referred to as a form of restoration; however, the science of ecosystem creation is in its infancy. There is no evidence that streams can be created de novo and results from wetland creation efforts suggest that while mitigation projects may meet compliance requirements, full ecological or functional success is low or unknown for most projects (Ambrose et al. 2007; Euliss et al. 2008; Mathews and Endress 2008). A 2008 review prepared for congress stated: "Both scientists and policymakers debate whether it is possible to restore or create wetlands with ecological and other functions equivalent to or better than those of natural wetlands that have been lost over time. [Yet] congress has repeatedly endorsed mitigation in recent years" (Copeland and Zinn 2008). Clearly, the social pressure is strong for ecosystem creation and scientists have an important role to play in determining the environmental implications. Ecologists, working in concert with hydrologists and engineers, need to determine the spatial contexts in which restoration projects are most likely to succeed and how local conditions influence functioning, especially biogeochemical.

\section{Conclusions}

Politics and social agendas will always influence the desired endpoints of a restoration effort, but the process by which restoration is done should be science driven. I have argued that science is not currently playing the role it should and that this is not just due to a lack of political or social will by the public. Instead, much of the science we have produced has not been effectively communicated to the potential users, or, more commonly, the science is not yet at the translation stage-i.e. implementing a general 
scientific finding in a specific restoration context is difficult. Scientists typically approach applied research by asking: how can my research be useful to managers and restoration practitioners? I suggest turning that question around by asking: what restoration science is being demanded? What are the applications in need of science? Is there quantitative evidence that methods currently being used are in fact ecologically effective? When science is viewed in this supply vs. demand framework (Sarewitz and Pielke 2007), restoration will become scientifically informed more quickly. I am also convinced that the science that is done in the process will contribute substantially to our fundamental understanding of watersheds. Many of the issues I have raised as central to reforming restoration are also central to ecological science-e.g. what is the relationship between ecosystem structure and function?

We are at an unusual time in the history of ecology in which our knowledge and theories are in great demand. Concerns over environmental sustainability are at an all time high, and there is a growing recognition that technological fixes won't solve all the problems. Ecological science can provide unique insights into how nature solves complex problems and how we can capitalize on those methods. So, rather than allowing other scientists from other fields to coopt the role of ecologists in advancing restoration science (e.g. eco-bio-engineers, and I don't mean the beaver kind), let's step up to the plate and take on the challenges.

Acknowledgements I thank the organizers of the 2007 Estuarine Research Federation international meetings for inviting me to present a talk that stimulated this paper. I also thank those in my research lab who continually stimulate me with new ideas. Jim Cloern, Carlos Duarte, and Si Simenstad provided very helpful comments. This paper is Contribution number 4233 from the University of Maryland Center for Environmental Science.

\section{References}

Ambrose, R.F., J. C. Callaway, and S.F. Lee. 2007. An Evaluation of Compensatory Mitigation Projects Permitted Under Clean Water Act Section 401 by the California State Water Resources Control Board, 1991-2002. Final report to the Water Resources Control Board of California.

Bain, D.J., S.M.C. Smith, and G.N. Nagle. 2008. Reservations about dam findings. Science 321: 910. doi:10.1126/science.321.5891.910a.

Berkes, R., J. Colding, and C. Folke (Editors). 2003. Navigating socio-ecological systems: building resilience for complexity and change. Cambridge University Press, Cambridge.

Bernhardt, E.S., M.A. Palmer, J.D. Allan, G. Alexander, S. Brooks, J. Carr, C. Dahm, J. Follstad-Shah, D.L. Galat, S. Gloss, P. Goodwin, D. Hart, B. Hassett, R. Jenkinson, G.M. Kondolf, S. Lake, R. Lave, J.L. Meyer, T.K. O'Donnell, L. Pagano, P. Srivastava, and E. Sudduth. 2005. Restoration of U.S. Rivers: a national synthesis. Science 308: 636-637. doi:10.1126/science.1109769.

Bernhardt, E.S., E.B. Sudduth, M.A. Palmer, J.D. Allan, J.L. Meyer, and G. Alexander. 2007. Restoring rivers one reach at a time: results from a survey of U.S. river protection practitioners. Restoration Ecology 15: 482-494. doi:10.1111/j.1526-100X. 2007.00244.x.

Berry, W., N. Rubinstein, B. Melzian, and B. Hill. 2003. The Biological Effects of Suspended and Bedded Sediment (SABS) in Aquatic Systems: A Review. An internal EPA report. http:// www.epa.gov/waterscience/criteria/sediment/pdf/appendix1.pdf. Accessed 27 July 2008.

Boesch, D.F. 2006. Scientific requirements for ecosystem-based management in the restoration of Chesapeake Bay and Coastal Louisiana. Ecological Engineering 26: 6-26. doi:10.1016/j. ecoleng.2005.09.004.

Boström, C., E.L. Jackson, and C.A. Simenstad. 2006. Seagrass landscapes and their effects on associated fauna: a review. Estuarine, Coastal and Shelf Science 68: 383-403. doi:10.1016/ j.ecss.2006.01.026.

Bottom, D.L., K.K. Jones, T.J. Cornwell, A. Gray, and C.A. Simenstad. 2005. Patterns of Chinook salmon migration and residency in the Salmon River estuary (Oregon). Estuarine, Coastal and Shelf Science 64: 79-93. doi:10.1016/j.ecss.2005.02.008.

Brooks, R.P., D.H. Wardrop, and J.A. Bishop. 2004. Assessing wetland condition on a watershed basis in the Mid Atlantic region using synoptic land cover maps. Environmental Monitoring and Assessment 94: 9-22. doi:10.1023/B:EMAS.0000016876.63062.3d.

Brown, B.L. 2003. Spatial heterogeneity reduces temporal variability in stream insect communities. Ecology Letters 6: 316-325. doi:10.1046/j.1461-0248.2003.00431.x.

Brush, G.S. 2008. Historical Land Use, Nitrogen, and Coastal Eutrophication: A Paleoecological Perspective. Estuaries and Coasts. doi:10.1007/s12237-008-9106-Z

Bunn, S.E., E.G. Abal, P.F. Greenfield, and D.M. Tarte. 2007. Making the connection between healthy waterways and healthy catchments: South East Queensland, Australia. Water Science and Technology: Water Supply 7: 93-100. doi:10.2166/ ws.2007.044.

Bunt, C.M., H.J. MacIsaac, and W.C. Sprules. 1993. Pumping rates and projected filtering impacts of juvenile zebra mussels (Dreissena polymorpha) in western Lake Erie. Canadian Journal of Fisheries and Aquatic Science 50: 1017-1022. doi:10.1139/f93-117.

CalFed. 2008. The California Bay-Delta Ecosystem Restoration Program. http://www.delta.dfg.ca.gov/erp/. Last accessed 12-02-08.

Cardinale, B.J., and M.A. Palmer. 2002. Disturbance moderates biodiversity - ecosystem function relationships: experimental evidence from caddisflies in stream mesocosms. Ecology 83: 1915-1927.

Cardinale, B.J., K. Nelson, and M.A. Palmer. 2001. Linking species diversity to the functioning of ecosystems: on the importance of environmental context. Oikos 91: 175-193. doi:10.1034/j.16000706.2000.910117.x.

Cardinale, B.J., M.A. Palmer, C.M. Swan, S. Brooks, and N.L. Poff. 2002. The influence of physical habitat on the rates of biofilm metabolism in a stream ecosystem. Ecology 83: 412-422.

Cardinale, B.J., D.S. Srivastava, J.E. Duffy, J.P. Wright, A.L. Downing, M. Sankaran, and C. Jouseau. 2006. Effects of biodiversity on the functioning of trophic groups and ecosystems. Nature 443: 989992. doi:10.1038/nature05202.

Carpenter, S.R., D. Ludwig, and W.A. Brock. 1999. Management of eutrophication for lakes subject to potentially irreversible change. Ecological Applications 9: 751-771. doi:10.1890/1051-0761 (1999)009[0751:MOEFLS]2.0.CO;2.

Carter, R.W.G., and C.D. Woodroffe (Editors). 1994. Coastal evolution. Cambridge University Press. Cambridge.

Chambers, J.C., and A.R. Linnerooth. 2001. Restoring riparian meadows currently dominated by Artemesia using alternative state concepts - the establishment component. Applied Vegetation Science 4: 157-166. 
Chesapeake Bay Program (CBP). 2007. What are tributary strategies? http://archive.chesapeakebay.net/pubs/tribstrats_backgrounder_ final.pdf. Accessed 27 July 2008.

Cloern, J.E., A.D. Jassby, J.K. Thompson, and K.A. Hieb. 2007. A cold phase of the East Pacific triggers new phytoplankton blooms in San Francisco Bay. Proceedings of the National Academy of Science 104: 18561-18565. doi:10.1073/pnas.0706151104.

Cole, C.A. 2006. HGM and wetland functional assessment: Six degrees of separation from the data? Ecological Indicators 6: 485-493. doi:10.1016/j.ecolind.2005.06.004.

Copeland, J.A., and C. Zinn. 2008. Wetlands: an overview of issues. Congressional Review Service publication RL33483, www. nationalaglawcenter.org/assets/crs/RL33483.pdf. Accessed online November 5, 2008.

Craig, L.S., M.A. Palmer, D.C. Richardson1, S. Filoso, E.S. Bernhardt, B.P. Bledsoe4, M.W. Doyle, P.M. Groffman, B. Hassett, S.S. Kaushal, P.M. Mayer, S.M. Smith, and P.R. Wilcock. 2008. Stream restoration strategies for reducing nitrogen loads. Frontiers in Ecology and the Environment 6. doi:10.1890/070080

Davidar, P., K. Yoganand, and T. Ganesh. 2001. Distribution of forest birds in the Andaman islands: importance of key habitats. Journal of Biogeography 8: 663-671. doi:10.1046/j.13652699.2001.00584.x.

DeAngelis, D.L., and J.C. Waterhouse. 1987. Equilibrium and nonequilibrium concepts in ecological models. Ecological Monographs 57: 1-21. doi:10.2307/1942636.

Duarte, C., and D.J. Conley. 2008. Return to Neverland: Shifting Baselines Affect Eutrophication Restoration Targets. Estuaries and Coasts. doi:10.1007/s12237-008-9111-2

Dudgeon, D. 2005. River management for conservation of freshwater biodiversity in monsoonal Asia. Ecology and Society 10: 15 . [online] http://www.ecologyandsociety.org/vol10/iss2/art15/.

Ehrenfeld, J.G., and L. Toth. 1997. Restoration ecology and the ecosystem perspective. Restoration Ecology 5: 307-317. doi:10.1046/j.1526-100X.1997.00544.x.

Elmqvist, T., C. Folke, M. Nyström, G. Peterson, J. Bengtsson, B. Walker, and J. Norberg. 2003. Response diversity, ecosystem change, and resilience. Frontiers in Ecology and Environmental Science 1: 488-494.

Environmental Protection Agency (EPA). 2006. Wadeable stream assessment: A Collaborative Survey of the Nation's Streams. EPA 841-B-06-002. http:/www.epa.gov/owow/streamsurvey/ pdf/WSA Assessment May2007.pdf. Accessed 27 July 2008.

Euliss, N.H. Jr., L.M. Smith, D.A. Wilcox, and B.A. Browne. 2008. Linking ecological processes with wetland management goals: charting a course for a sustainable future. Wetlands 28: 553-562. doi:10.1672/07-154.1.

Falk, D.A., C.M. Richards, A.M. Montalvo, and E.E. Knapp. 2006. Population and ecological genetics in restoration ecology. In Foundations of restoration ecology. 14-41, Washington, D.C.: Island Press.

Federal Register 2008. U.S. EPA and U.S. ACOE Compensatory Mitigation for Losses of Federal Register. 2008. Aquatic Resources. Vol. 73 (70) April 10, 2008/Rules and Regulations. http://www.epa. gov/owow/wetlands/pdf/wetlands_mitigation_final_rule_4_10_08. pdf. Last accessed online November 5, 2008.

Fellows, C.S., J.E. Clapcott, J.W. Udy, S.E. Bunn, B.D. Harch, M.J. Smith, and P.M. Davies. 2006. Benthic metabolism as an indicator of stream ecosystem health. Hydrobiologia 572: 7187. doi:10.1007/s10750-005-9001-6.

Florsheim, J.K., J.F. Mount, and A. Chin. 2008. Bank erosion as a desirable attribute of rivers. BioScience 58: 519-529. doi:10.1641/B580608.

Gorshkov, Y.A., A.L. Easter-Pilcher, B.K. Pilcher, and D. Gorshkov. 1999. Ecological restoration by harnessing the work of beaver. In
Beaver protection, management, and utilization in Europe and North America, eds. Busher, P.E. and R.M. Dzieciolowski, 6785. NY: Plenum Publishers.

Grabowski, J.H. 2004. Habitat complexity disrupts predator-prey interactions but not the trophic cascade on oyster reefs. Ecology 85: 995-1004. doi:10.1890/03-0067.

Grabowski, J.H., and C.H. Peterson. 2007. Restoring oyster reefs to recover ecosystem services. In Ecosystem engineers: concepts, theory and applications, eds. Cuddington, K., J.E. Byers, W.G. Wilson, and A. Hastings, 281-298. Amsterdam: Elsevier-Academic Press.

Grant, E.H.C., W.H. Lowe, and W.F. Fagan. 2007. Living in the branches: population dynamics and ecological processes in dendritic networks. Ecology Letters 10: 165-175. doi:10.1111/ j.1461-0248.2006.01007.x.

Gutshall, M. 2004. Back to the Future: Stream Corridor Restoration and Some New Uses for Old Floodplains. A Landstudies, Inc. Report. http://www.landstudies.com/BacktotheFuture.pdf. Accessed July 162008.

Hanski, I., and O. Gaggiotti. 2004. The ecology, genetics and evolution of metapopulations. San Diego: Academic Press.

Harding, J.M., and R. Mann. 2001. Oyster reefs as fish habitat: Opportunistic use of restored reefs by transient fishes. Journal of Shellfish Research 20: 951-959.

Hassett, B., M.A. Palmer, E.S. Bernhardt, S. Smith, J. Carr, and D. Hart. 2005. Status and trends of river and stream restoration in the Chesapeake Bay watershed. Frontiers in Ecology and the Environment 3: 259-267.

Hector, A., and R. Bagchi. 2007. Biodiversity and ecosystem multifunctionality. Nature 448: 188-191. doi:10.1038/nature05947.

Hentschel, B.T., and A.A. Larson. 2005. Growth rates of interfacefeeding polychaetes: combined effects of flow speed and suspended food concentration. Marine Ecology Progress Series 293: 119-129. doi:10.3354/meps293119.

Hobbs, R.J., and D.A. Norton. 1996. Towards a conceptual framework for restoration ecology. Restoration Ecology 4: 93-110. doi:10.1111/j.1526-100X.1996.tb00112.x.

Hoegh-Guldberg, O., L. Hughes, S. McIntyre, D. Lindenmayer, C. Parmesan, H. Possingham, and C.D. Thomas. 2008. Climate change and assisted colonization. Science 321: 345-346. doi: $10.1126 /$ science. 1157897.

Hooper, D.U., F.S. Chapin III, J.J. Ewel, A. Hector, P. Inchausti, S. Lavorel, J.H. Lawton, D. Lodge, M. Loreau, S. Naeem, B. Schmid, H. Setälä, A.J. Symstad, J. Vandermeer, and D.A. Wardle. 2005. Effects of biodiversity on ecosystem functioning: A consensus of current knowledge. Ecological Monographs 75: 3-35. doi:10.1890/04-0922.

Hughes, F.M.R., A. Colston, and J.O. Mountford. 2005. Restoring Riparian Ecosystems: The Challenge of Accommodating Variability and Designing Restoration Trajectories. Ecology and Society 10: 12. [online] URL: http://www.ecologyandsociety. org/vol10/iss1/art12/.

Hutchinson, G.E. 1959. Homage to Santa-Rosalia or why are there so many kinds of animals. American Naturalist 93: 145. doi: $10.1086 / 282070$.

Kaiser, M.J., S.I. Rogers, and J.R. Ellis. 1999. Importance of benthic habitat complexity for demersal fish assemblages in Fish habitat: essential fish habitat and rehabilitation. In American fisheries society, symposium 22, eds. Benaka, L.R., 212-223. Maryland: Bethesda.

Katz, S., K. Barnas, V.R. Hicks, J. Cowen, and R. Jenkinson. 2007. Freshwater habitat restoration actions in the Pacific Northwest: a 10-year census. Restoration Ecology 15: 506-515. doi:10.1111/ j.1526-100X.2007.00245.x.

Kaushal, S.S., P.M. Groffman, P.M. Mayer, E. Striz, E.J. Doheny, and A.J. Gold. 2008. Effects of stream restoration on denitrification at 
the riparian-stream interface of an urbanizing watershed of the mid-Atlantic U.S. Ecological Applications 18: 789-804. doi:10.1890/07-1159.1.

Keitt, T.H. 2008. Coherent ecological dynamics induced by large-scale disturbance. Nature 454: 331-334. doi:10.1038/nature06935.

Kondolf, M. 2006. River restoration and meanders. Ecology and Society 11(2): 42. [online] URL: http://www.ecologyandsociety. org/vol11/iss2/art42/.

Lake, P.S., N. Bond, and P. Reich. 2007. Linking ecological theory with stream restoration. Freshwater Biology 52: 597-615. doi:10.1111/j.1365-2427.2006.01709.x.

Larkin, D.J., G. Vivian-Smith, and J.B. Zedler. 2006. Topographic heterogeneity theory and ecological restoration. In Foundations of restoration ecology, eds. Falk, D.A., M.A. Palmer, and J.B. Zedler, 142-164. Washington, DC: Island Press.

Larkin, D.J., S.P. Madon, J.M. West, and J.B. Zedler. 2008. Topographic heterogeneity influences fish use of an experimentally restored tidal marsh. Ecological Applications 18: 483-496. doi:10.1890/06-1984.1.

Lepori, F., D. Palm, E. Brannas, and B. Malmqvist. 2005. Does restoration of structural heterogeneity in streams enhance fish and macroinvertebrate diversity? Ecological Applications 15: 20602071. doi:10.1890/04-1372.

Leslie, H.M., and K.L. McLeod. 2007. Confronting the challenges of implementing marine ecosystem-based management. Frontiers in Ecology and the Environment 5: 540-548. doi:10.1890/060093.

Lewontin, R.C. 1969. The meaning of stability. Brookhaven Symposium in Biology 22: 13-23.

Li, H., and J.F. Reynolds. 1995. On definition and quantification of heterogeneity. Oikos 73: 280-284. doi:10.2307/3545921.

Liu, J.G., T. Dietz, S.R. Carpenter, M. Alberti, C. Folke, E. Moran, A.N. Pell, P. Deadman, et al. 2007. Complexity of coupled human and natural systems. Science 317: 1513-1516. doi:10.1126/science.1144004.

Loreau, M., and N. Behera. 1999. Phenotypic diversity and stability of ecosystem processes. Theoretical Population Biology 56: 29-47. doi:10.1006/tpbi.1998.1408.

Lotze, H.K., H.S. Lenihan, B.J. Bourque, R.H. Bradbury, R.G. Cooke, M.C. Kay, S.M. Kidwell, M.X. Kirby, C.H. Peterson, and J.B.C. Jackson. 2006. Depletion, degradation, and recovery potential of estuaries and coastal seas. Science 312: 1806-1809. doi:10.1126/ science. 1128035

Lowe, A., S. Harris, and P. Ashton. 2004. Ecological genetics: design, analysis, and application. Oxford: Blackwell Publishing.

Luckenbach, M.W., M.R. Mann, and J.A. Wesson. 1999. Oyster reef habitat restoration: a synopsis and synthesis of approaches. Proceedings from the symposium, Williamsburg, VA. Virginia Institute of Marine Science Press, Gloucester Point, VA.

MacArthur, R.H., and J.W. MacArthur. 1961. On bird species diversity. Ecology 42: 595-599.

MacArthur, R.H., and E.O. Wilson. 1967. The theory of island biogeography. Princeton, N.J.: Princeton University Press.

Machado-Schiaffino, G., E. Dopico, and E. Garcia-Vazquez. 2007. Genetic variation losses in Atlantic salmon stocks created for supportive breeding. Aquaculture 264: 59-65. doi:10.1016/j. aquaculture.2006.12.026.

MacNally, R., and D.M. Watson. 2006. Distinguishing area and habitat heterogeneity effects on species richness: birds in Victorian buloke remnants. Australia Ecology 22: 227-232.

Mann, R., and E.N. Powell. 2007. Why oyster restoration goals in the Chesapeake Bay are not and probably cannot be achieved. Journal of Shellfish Research 26: 905-917. doi:10.2983/07308000(2007)26[905:WORGIT]2.0.CO;2.

Maryland Department of the Environment (MDE). 2004. List of Impaired Surface Waters [303(d) List] and Integrated Assessment of Water Quality in Maryland. http://www.mde.state.md.us/ assets/document/Cover_TableofContents_2004-303d_Final.pdf. Accessed November 4, 2008.

Maschinski, J., and S.J. Wright. 2006. Using ecological theory to plan restorations of the endangered Beach jacquemontia (Convolvulaceae) in fragmented habitats. Journal for Nature Conservation 14: 180-189. doi:10.1016/j.jnc.2006.05.003.

Mathews, J.W., and A.G. Endress. 2008. Performance criteria, compliance success, and vegetation development in compensatory mitigation wetlands. Environmental Management 41: 130 141. doi:10.1007/s00267-007-9002-5.

Matthaei, C.D., W. Florian, D.W. Kely, and C.R. Townsend. 2006. Impacts of fine sediment addition to tussock, pasture, dairy and deer farming streams in New Zealand. Freshwater Biology 51: 2154-2172. doi:10.1111/j.1365-2427.2006.01643.x.

May, R., and A. McLean (editors). 2007. Theoretical ecology: principles and applications. Oxford University Press, $251 \mathrm{pp}$.

Mayer, A.L., and M. Rietkerk. 2004. The dynamic regime concept for ecosystem management and restoration. BioScience 54: 10131020. doi:10.1641/0006-3568(2004)054[1013:TDRCFE]2.0.CO;2.

McCann, K.S. 2000. The diversity-stability debate. Nature 405: 228 233. doi: $10.1038 / 35012234$.

McCarthy, M.A., C.J. Thompson, and H.P. Possingham. 2005. Theory for designing nature reserves for single species. American Naturalist 165: 250-257. doi:10.1086/427297.

McGlade, J.M. 1999. Advanced ecological theory: principles and applications. Oxford: Blackwell Publishing. 353 pp.

Montgomery, D.R. 2008. Dreams of natural streams. Science 319: 291-192. doi:10.1126/science.1153480

Mouquet, N., and M. Loreau. 2003. Community patterns in sourcesink metacommunities. American Naturalist 162: 544-557. doi: $10.1086 / 378857$.

Murdoch, W.W., F.C. Evans, and C.H. Peterson. 1972. Diversity and pattern in plants and insects. Ecology 53: 819-829. doi:10.2307/ 1934297.

Naeem, S. 2006. Biodiversity and ecosystem functioning in restored ecosystems: extracting principles for a synthetic perspective. In Foundations of restoration ecology, eds. Falk, D., M. Palmer, and J. Zedler, 219-237. Washington, DC: Island Press.

Naeem, S., L.J. Thompson, S.P. Lawler, J.H. Lawton, and R.M. Woodfin. 1994. Declining biodiversity can alter the performance of ecosystems. Nature 368: 734-737. doi:10.1038/368734a0.

Nakano, S., and M. Murakami. 2001. Reciprocal subsidies: dynamic interdependence between terrestrial and aquatic food webs. Proceedings of the National Academies of Science 98: 166170. doi:10.1073/pnas.98.1.166.

Nelson, K.A., L.A. Leonard, M.H. Posey, T.D. Alphin, and M.A. Mallin. 2004. Using transplanted oyster (Crassostrea virginica) beds to improve water quality in small tidal creeks: a pilot study. Journal of Experimental Marine Biology and Ecology 298: 347368. doi:10.1016/S0022-0981(03)00367-8.

Palmer, M.A., and E.S. Bernhardt. 2006. Hydroecology and river restoration: ripe for research and synthesis. Water Resources Research 42: W03S07. doi:10.1029/2005WR004354.

Palmer, M.A., R. Ambrose, and N.L. Poff. 1997. Ecological theory and community restoration ecology. Restoration Ecology 5: 291300. doi:10.1046/j.1526-100X.1997.00543.x.

Palmer, M.A., E. Bernhardt, E. Chornesky, S. Collins, A. Dobson, C. Duke, B. Gold, R. Jacobson, S. Kingsland, R. Kranz, M. Mappin, M.L. Martinez, F. Micheli, J. Morse, M. Pace, M. Pascual, S. Palumbi, O.J. Reichman, A. Simons, A. Townsend, and M. Turner. 2004. Ecology for a crowded planet. Science 304: 12511252. doi:10.1126/science. 1095780.

Palumbi, S.R. 2003. Ecological subsidies alter the structure of marine communities. Proceedings of the National Academies of Science 100: 11927-11928. doi:10.1073/pnas.2335832100. 
Parker, K.R., and J.A. Wiens. 2005. Assessing recovery following environmental accidents: environmental variation, ecological assumptions, and strategies. Ecological Applications 15: 20372051. doi:10.1890/04-1723.

Pimm, S.L. 1991. The balance of nature? Ecological issues in the conservation of species and communities. Chicago, Illinois: University of Chicago Press.

Polis, G.A., and S.D. Hurd. 1996. Linking marine and terrestrial food webs: allochthonous input from the ocean supports high secondary. American Naturalist 147: 396-423. doi:10.1086/ 285858.

Poole, G.C., J.B. Dunham, U.M. Keenan, S.T. Sauter, D.A. McCullough, C. Mebane, J.C. Lockwood, D.A. Essig, M.P. Hicks, D.J. Sturdevant, E.J. Materna, S.A. Spalding, J. Risley, and M. Deppman. 2004. The case for regime-based water quality standards. Bioscience 54: 155-161. doi:10.1641/0006-3568(2004)054[0155: TCFRWQ]2.0.CO;2.

Postel, S., and B. Richter. 2003. Rivers for life: managing water for people and nature. Washington, D.C.: Island Press.

Power, M.E., D. Tilman, J.A. Estes, B.A. Menge, W.J. Bond, L.S. Mills, J. Daily, J.C. Castillo, J. Lubchenco, and R. Paine. 1996. Challenges in the quest for keystones. Bioscience 46: 609-620. doi: $10.2307 / 1312990$.

Pretty, J.L., S.S.C. Harrison, D.J. Shepherd, C. Smith, A.G. Hildrew, and R.D. Hey. 2003. River rehabilitation and fish populations: assessing the benefit of in-stream structures. Journal of Applied Ecology 40: 251-265.

Rheinhardt, R.D., M.M. Brinson, and P.M. Farley. 1997. Applying wetland reference data to functional assessment, mitigation, and restoration. Wetlands 17: 195-215.

Roberts, B.J., P.J. Mulholland, and J.N. Houser. 2008. Effects of upland disturbance and in-stream restoration on hydrodynamics and ammonium uptake in headwater streams. Journal of the North American Benthological Society 26: 38-53. doi:10.1899/ 0887-3593(2007)26[38:EOUDAI]2.0.CO;2.

Roni, P.T., J. Beechie, R.E. Bilby, F.E. Leonetti, M.M. Pollock, and G.R. Pess. 2002. A review of stream restoration techniques and a hierarchical strategy for prioritizing restoration. Pacific Northwest Watersheds North American Journal of Fisheries Management 22: 1-20.

Rosgen, D. 1996. Applied river morphology. Wildland Hydrology. Lakewood: Colorado.

Sarewitz, D., and R. Pielke Jr. 2007. The neglected heart of science policy: reconciling supply of and demand for science. Environmental Science and Policy 10: 5-16. doi:10.1016/j.envsci.2006.10.001.

Schneider, K.N., and K.O. Winemiller. 2008. Structural complexity of woody debris patches influences fish and macroinvertebrate species richness in a temperate floodplain-river system. Hydrobiologia 610: 235-244. doi:10.1007/s10750-008-9438-5.

Scoones, I., and C. Toulmin. 1998. Soil nutrient balances: what use for policy? Agriculture, Ecosystems and Environment 71: 255-267. doi:10.1016/S0167-8809(98)00145-5.

Shurin, J.B. 2000. Dispersal limitation, invasion resistance, and the structure of pond zooplankton communities. Ecology 81: 30743086.

Shurin, J.B., S.E. Arnott, H. Hillebrand, A. Longmuir, B. Pinel-Alloul, M. Winder, and N.D. Yan. 2007. Diversity-stability relationship varies with latitude. Ecology Letters 10: 127-134. doi:10.1111/ j.1461-0248.2006.01009.x.

Simenstad, C., D. Reed, and M. Ford. 2006. When is restoration not? Incorporating landscape-scale processes to restore self-sustaining ecosystems in coastal wetland restoration. Ecological Modelling 26: $27-39$.

Sirota, L., and S.A. Hovel. 2006. Simulated eelgrass Zostera marina structural complexity: effects of shoot length, shoot density, and surface area on the epifaunal community of San Diego Bay,
California, USA. Marine Ecology Progress Series 326: 115-131. doi:10.3354/meps326115.

Smith, R.F., and W.O. Lamp. 2008. Comparison of insect communities between adjacent headwater and main-stem streams in urban and rural watersheds. Journal of North American Benthological Society 27: 161-175. doi:10.1899/07-071.1.

Smith, S.M., and K.L. Prestegaard. 2005. Hydraulic performance of a morphology based stream channel design. Water Resources Research 41: W11413. doi:10.1029/2004WR003926.

Spänhoff, B., and J. Arle. 2007. Setting attainable goals of stream habitat restoration from a macroinvertebrate view. Restoration Ecology 15: 317-320. doi:10.1111/j.1526-100X.2007.00216.x.

Stachowicz, J.J., J.F. Bruno, and J.E. Duffy. 2007. Understanding the effects of marine biodiversity on communities and ecosystems. Annual Review of Ecology and Systematics 38: 739-766. doi:10.1146/annurev.ecolsys.38.091206.095659.

Stanley, E., and M. Doyle. 2003. Trading off: the ecological effects of dam removal. Frontiers in the Ecology and Environment 1: 15-22.

Steyer, G.C., C.E. Sasser, J.M. Visser, E.M. Swenson, J.A. Nyman, and R.C. Raynie. 2003. A proposed coast-wide reference monitoring system for evaluating wetland restoration trajectories in Louisiana. Environmental Monitoring and Assessment 81: 107-111. doi:10.1023/A:1021368722681.

Suding, K.N., and K.L. Gross. 2006. The dynamic nature of ecological systems: multiple states and restoration trajectories. In Foundation of restoration ecology, eds. Falk, D., M.A. Palmer, and J.B. Zedler, 190-209. Washington, DC: Island Press.

Suding, K.N., K.L. Gross, and G.R. Houseman. 2004. Alternative states and positive feedbacks in restoration ecology. Trends in Ecology and Evolution 19: 46-53. doi:10.1016/j.tree.2003.10.005.

Tews, J., U. Brose, V. Grimm, K. Tielbörger, M.C. Wichmann, M. Schwager, and F. Jeltsch. 2004. Animal species diversity driven by habitat heterogeneity/diversity: the importance of keystone structures. Journal of Biogeography 31: 79-92.

Tilman, D., D. Wedin, and J. Knops. 1996. Productivity and sustainability influenced by biodiversity in grassland ecosystems. Nature 379: 718-720. doi:10.1038/379718a0.

Travis, S.E., C.E. Proffitt, R.C. Lowenfeld, and T.W. Mitchell. 2002. Comparative assessment of genetic diversity among differentlyaged populations of Spartina alterniflora on restored versus natural wetlands. Restoration Ecology 10: 37-42. doi:10.1046/ j.1526-100X.2002.10104.x.

Turner, M.G., and R.H. Gardner. 1991. Quantitative methods in landscape ecology. New York: Springer Verlag.

Vivian-Smith, G. 1997. Microtopographic heterogeneity and floristic diversity in experimental wetland communities. Journal of Ecology 85: 71-82. doi:10.2307/2960628.

Walker, B., and J.A. Meyers. 2004. Thresholds in ecological and socialecological systems: a developing database. Ecology and Society 9(2): 3. [online] URL: http://www.ecologyandsociety.org/vol9/iss2/art3/.

Walker, B., S. Carpenter, J. Anderies, N. Abel, G.S. Cumming, M. Janssen, L. Lebel, J. Norberg, G.D. Peterson, and R. Pritchard. 2002. Resilience management in social-ecological systems: a working hypothesis for a participatory approach. Conservation Ecology 6(1): 14. [online] URL: http://www.consecol.org/vol6/iss1/art14/.

Walker, B., C.S. Holling, S.R. Carpenter, and A. Kinzig. 2004. Resilience, adaptability and transformability in social-ecological systems. Ecology and Society 9(2): 5. [online] URL: http://www. ecologyandsociety.org/vol9/iss2/art5/.

Walsh, C.J., A.H. Roy, J.W. Feminella, P.D. Cottingham, P.M. Groffman, and R.P. Morgan. 2005. The urban stream syndrome: current knowledge and the search for a cure. Journal of The North American Benthological Society 24: 706-723.

Walter, R.C., and D.J. Merritts. 2008. Natural streams and the legacy of water-powered mills. Science 319: 299-304. doi:10.1126/ science. 1151716. 
Weiner, J. 1995. On the practice of ecology. Journal of Ecology 83: 153-158. doi:10.2307/2261159.

Weller, D.E., M.N. Snyder, D.F. Whigham, A.D. Jacobs, and T.E. Jordan. 2007. Landscape indicators of wetland condition in The Nanticoke River Watershed, Maryland and Delaware, USA. Wetlands 27: 498-514. doi:10.1672/0277-5212(2007)27[498: LIOWCI]2.0.CO;2.

Wellnitz, T., and N.L. Poff. 2001. Functional redundancy in heterogeneous environments: implications for conservation. Ecological Letters 4: 177-179. doi:10.1046/j.1461-0248.2001. 00221.x.

White, P.S., and J.S. Walker. 1997. Approximating nature's variation: selecting and using reference information in restoration ecology. Restoration Ecology 5: 338-349. doi:10.1046/j.1526-100X. 1997.00547.x.
Williams, S.L. 2001. Reduced genetic diversity in eelgrass transplantations affects both population growth and individual fitness. Ecological Applications 11: 1472-1488. doi:10.1890/1051-0761 (2001)011[1472:RGDIET]2.0.CO;2.

Willis, S.C., K.O. Winemiller, and H. Lopez-Fernandez. 2005. Habitat structural complexity and morphological diversity of fish assemblages in a Neotropical floodplain river. Oecologia 142: 1432-1939. doi:10.1007/s00442-004-1723-z.

Wu, J., and O. Loucks. 1995. From balance of nature to hierarchical patch dynamics: a paradigm shift in ecology. Annual Review of Biology 70: 439-466.

Zedler, J.B. 2000. Progress in wetland restoration ecology. Trends in Ecology and Evolution 15: 402-407. doi:10.1016/S0169-5347 (00)01959-5. 